\title{
Optimization of aqueous extraction conditions for bioactive compounds from fresh Pouzolzia zeylanica plant using response surface methodology
}

\author{
Tan D. Nguyen ${ }^{1,2}$ \\ ${ }^{1}$ Faculty of Agriculture and Natural Resources, An Giang University, An Giang, Vietnam \\ ${ }^{2}$ Vietnam National University, Ho Chi Minh City, Vietnam
}

\section{ARTICLE INFO}

Research Paper

Received: March 02, 2020

Revised: May 20, 2020

Accepted: June 22, 2020

Keywords

Bioactive compounds

Extraction temperature

Extraction time

Pouzolzia zeylanica plant

Response surface methodology

\section{Corresponding author}

Nguyen Duy Tan

Email: ndtan@agu.edu.vn

ABSTRACT

Response surface methodology was applied to optimize the extraction of phenolic compounds from fresh Pouzolzia zeylanica plant using hot water as a solvent. A central composite design (CCD) in form $\left(2^{3}+\right.$ star $)$ was used to investigate the effects of two independent variables, namely, extraction temperature $\left(70\right.$ to $\left.90^{\circ} \mathrm{C}\right)$ and extraction time $(20$ to $40 \mathrm{~min})$. The dependent variables were the content of anthocyanin, flavonoid, polyphenol, tannin and total soluble solids of extracted solution. A second-order polynomial model was used for predicting the response. The results showed that the optimal extraction process was obtained at $84.4^{\circ} \mathrm{C}$ for $31.7 \mathrm{~min}$. The experimental values agreed with predicted within a $95 \%$ confidence interval. Consequently, the contents of anthocyanin, flavonoid, polyphenol and tannin were $38.66 \mathrm{mgCE} / 100 \mathrm{~g}, 3.01$ $\mathrm{mgQE} / \mathrm{g}, 5.17 \mathrm{mgGAE} / \mathrm{g}, 4.07 \mathrm{mgTAE} / \mathrm{g}$ fresh weight, and total soluble solids content was $0.73 \%$, respectively.

Cited as: Nguyen, T. D. (2020). Optimization of aqueous extraction conditions for bioactive compounds from fresh Pouzolzia zeylanica plant using response surface methodology. The Journal of Agriculture and Development 19(3), 65-74.
\end{abstract}

\section{Introduction}

Pouzolzia zeylanica is a medicinal source that people of Asia countries have used to treat various kinds of diseases by traditional methods. In Vietnam, this plant was popularly cultivated in the Mekong Delta region, it can be used as fresh or dried plant, decoction drunk to treat cough, pulmonary tuberculosis, sore throat, enteritis and dysentery (Vo, 2012). Several in vitro researches have indicated ethanolic extracts of Pouzolzia zeylanica possessed antibacterial, antifungal and cytotoxic activities (Saha et al., 2012; Sara \& Paul, 2012); it had no oral acute toxic- ity at the oral dose of $10 \mathrm{~g}$ material powder $/ \mathrm{kg}$ (Tran et al., 2010). Traditionally, this plant was prepared as an infusion with water, to make tea.

Extraction is the separation of medicinally active portions of plant using selective solvents through standard procedures (Handa et al., 2008). The purpose of all extraction is to separate the soluble plant metabolites, leaving behind the insoluble cellular. The obtained crude extracts contain a complex mixture of many plant metabolites, such as alkaloids, glycosides, phenolics, terpenoids and flavonoids. Some of the initially obtained extracts may be ready for use as medicinal agents or beverages but some need fur- 
ther processing.

In addition, we have known since decades that chemical constituents as an extractable matter which obtained from the extraction process were influenced by extraction parameters, also influenced by the quality of the medicinal plant (Vyas et al., 2013). So, if the extraction process can be optimized in terms of bioactive compounds content such as anthocyanin, flavonoid, polyphenol and tannin. They could have had potential as beverages or concentrated products with medicinal properties. The presence of phenolic compounds in the extracted solution had effect on biological value of the final product. Therefore, it is necessary to determine the effects of extraction time and temperature on the content of phenolic compounds.

\section{Materials and Methods}

\subsection{Chemicals and reagents}

Folin-Ciocalteu, Folin-Denis reagents and quercetin, gallic acid, tannic acid were obtained from Sigma Chemical Co. (USA) and Merck Chemical Supplies (Germany). All the chemicals, including the solvents, were of analytical grade.

\subsection{Sample preparation and extraction}

Pouzolzia zeylanica plants were collected in April 2017 from a household in Hoa Binh village, Cho Moi district, An Giang province with $20-30 \mathrm{~cm}$ height. It was cleaned with tap-water, cut into small pieces about 2-3 cm long. After that, the samples of Pouzolzia zeylanica were extracted with water using an airtight extractor (model GPA CC1-181907, DidatecTechnologie France, 2007). Stirring rate was maintained at $90(\mathrm{rpm})$. The extract samples were fixed a volume of 5 liters and solution to the material ratio of $15: 1, \mathrm{v} / \mathrm{w}$. The samples were extracted at temperature of $\left(63,70,80,90\right.$ and $\left.97^{\circ} \mathrm{C}\right)$, in the duration of $(13,20,30,40$ and $47 \mathrm{~min})$. The extracts were filtered by cotton cloth and determined their volumes. Subsequently, the extracts were filtered using Buchner funnel with Whatman's No 1 filter paper. The crude extract was diluted at an appropriate ratio using for analysis.

\subsection{Experimental design and statistical anal- ysis}

In this study, response surface methodology (RSM) with central composite design (CCD) in form $\left(2^{3}+\right.$ star $)$ was used to investigate the effects of two independent variables: $X$ (extraction temperature) and $\mathrm{Y}$ (extraction time) on the extraction of anthocyanin, flavonoid, polyphenol and tannin contents. The independent variables were coded at five levels $(-\alpha,-1,0,+1,+\alpha)$ and the complete design consisted of 13 experimental points, including five replications of the center points (Table 1). The experimental design and statistical analysis were performed using Statgraphics plus 16.0 for Windows. A quadratic equation (second-order polynomial equation) was used to fit the results:

$\mathrm{Z}=\mathrm{b}_{0}+\mathrm{b}_{1} \mathrm{X}+\mathrm{b}_{2} \mathrm{Y}+\mathrm{b}_{1.2} \mathrm{XY}+\mathrm{b}_{1.1} \mathrm{X}_{2}+\mathrm{b}_{2.2} \mathrm{Y}_{2}$ Where $\mathrm{Z}$ is the predicted response parameter, bo is a constant, b1, b2, b1.1, b2.2 and b1.2 are the regression coefficients; $\mathrm{X}$ and $\mathrm{Y}$ are the levels of the independent variables (extraction temperature and time). Experimental data were then fitted to the selected regression model to achieve a proper understanding of the correlation between each factor and different responses. This correlation was obtained by estimating the numerical values of the model terms (regression coefficients), whose significance was statistically judged in accordance with t-statistic at a confidence interval of $95 \%$. Non-significant $(P>0.05)$ terms were deleted from the initial equation and data were refitted to the selected model. This work helped that the models will have a higher correlation coefficient $\mathrm{R}$. The compatibility of the mathematical models was fitted by RSM and evaluated by ANOVA, based on the F-test, the probability value $(P)$ of lack-of-fit and on the percentage of total explained variance $\left(\mathrm{R}^{2}\right)$, and also on the adjusted determination coefficient $\left(\mathrm{R}_{\mathrm{adj}}^{2}\right)$. These variances provide a measurement of the variability in the observed response values that could be explained by the experimental factors and their linear and quadratic interactions. Simultaneous optimization of the desirability function was performed in order to maximize the content of anthocyanin, flavonoid, polyphenol, tannin and soluble solids. 


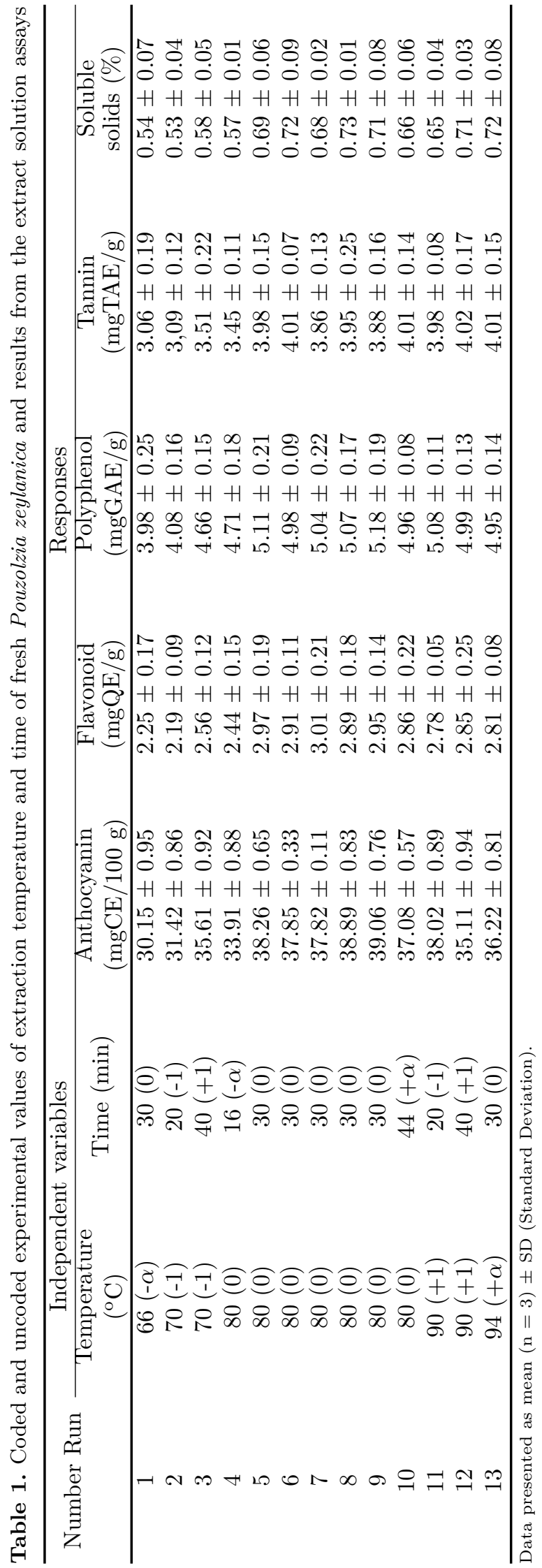

\subsection{Determination of chemical composition of Pouzolzia zeylanica L. Benn}

\subsubsection{Total anthocyanin content (mgCE/100 g FW)}

The determination of monomeric anthocyanin was conducted by $\mathrm{pH}$-differential method (Ahmed et al., 2013). The samples perform dilutions in $50 \mathrm{~mL}$ volumetric flasks. The volumetric pipets are used for addition of the test portion. The maximum test portion added should be $\leq$ $10 \mathrm{~mL}$ (the ratio of test/buffer is $1 / 4, \mathrm{v} / \mathrm{v}$ ) and not to exceed the buffer capacity of the reagents. The absorbance of test portion diluted with $\mathrm{pH}$ 1.0 buffer and $\mathrm{pH} 4.5$ buffer is determined at both $520 \mathrm{~nm}$ and $700 \mathrm{~nm}$. Total monomeric anthocyanins were expressed as cyanidin-3-glucoside. Sample absorbance was read against a blank cell containing distilled water. The absorbance (A) of the sample was then calculated according to the following formula:

$\mathrm{A}=\left(\mathrm{A}_{520}-\mathrm{A}_{700}\right) \mathrm{pH} 1.0-\left(\mathrm{A}_{520}-\mathrm{A}_{700}\right) \mathrm{pH} 4.5$

Total anthocyanin content (TAC) in the sample was calculated according to the following formula:

TAC $(\mathrm{mgCE} / 100 \mathrm{~g})=(\mathrm{A} \times \mathrm{MW} \times \mathrm{DF} \times \mathrm{V} \times$ $1000) /(\epsilon \times 1 \times \mathrm{W})$

Where DF is dillution factor, MW is cyanidin3 -glucoside molecular weight $(449,2), \epsilon$ is molar absorptivity $(26,900), \mathrm{V}$ is volume of the obtained extracts, in litre, $10^{3}$ is factor for conversion from $\mathrm{g}$ to $\mathrm{mg}, \mathrm{W}$ is the weight of material sample, in gram.

\subsubsection{Total flavonoid content (mg QE/g FW)}

Aluminum chloride colorimetric method was used for flavonoids determination (Eswari et al., 2013). About $1 \mathrm{~mL}$ of the crude extracts/standard of different concentrations was mixed with $3 \mathrm{~mL}$ ethanol, $0.2 \mathrm{~mL}$ of $10 \%$ aluminum chloride, $0.2 \mathrm{~mL}$ of $1 \mathrm{M}$ sodium acetate and $5.8 \mathrm{~mL}$ of distilled water. It remained at room temperature for $30 \mathrm{~min}$. The absorbance of the reaction mixture was measured at $415 \mathrm{~nm}$ with spectrophotometer against blank. The calibration curve was prepared by diluting quercetin in ethanol $\left(\mathrm{y}=0.0054 \mathrm{x}+0.0026\right.$ and $\left.\mathrm{r}^{2}=0.9995\right)$. The total flavonoid content (TFC), milligrams of quercetin equivalents $(\mathrm{QE})$ per gram fresh weight $(\mathrm{FW})$, was calculated by the following formula: $\mathrm{TFC}(\mathrm{mgQE} / \mathrm{g})=[(\mathrm{A}-0.0026) \times \mathrm{DF} \times \mathrm{V}] /$ 


\section{$(0.0054 \times \mathrm{W})$}

Where A is the absorbance of the test samples; DF is the dilution factor; $\mathrm{V}$ is volume of the obtained extracts, in litre; $\mathrm{W}$ is the weight of material sample, in gram.

\subsubsection{Total polyphenol content (mg GAE/g FW)}

Total polyphenol content was determined by Folin-Ciocalteu reagent method (Hossain et al., 2013). Each crude extract $(0.2 \mathrm{~mL})$ was taken in a test tube and added 10\% Folin-Ciocalteu reagent $(1.5 \mathrm{~mL})$. Then all test tubes were kept in a dark place for 5 min. Finally, $5 \% \mathrm{Na}_{2} \mathrm{CO}_{3}(1.5 \mathrm{~mL})$ was added to solution and mixed well in a vortex. Again, all the test tubes were kept in the dark for $2 \mathrm{~h}$. The absorbance was measured for all solutions by using UV-spectrophotometer at constant wavelength $750 \mathrm{~nm}$. Total polyphenol concentrations were quantified by a calibration curve obtained from measuring the absorbance of a known concentration of gallic acid standard in ethanol $\left(\mathrm{y}=0.0082 \mathrm{x}+0.0595\right.$ and $\left.\mathrm{R}^{2}=0.9996\right)$. The total polyphenol content (TPC), milligrams of gallic acid equivalents (GAE) per gram fresh weight $(\mathrm{FW})$, was calculated by the following formula:

$\mathrm{TPC}(\mathrm{mgGAE} / \mathrm{g})=[(\mathrm{A}-0.0595) \times \mathrm{DF}$ $\mathrm{xV}] /(0.0082 \times \mathrm{W})$

Where A is the absorbance of the test samples; $\mathrm{DF}$ is the dilution factor; $\mathrm{V}$ is the volume of the obtained extracts, in litre; $\mathrm{W}$ is the weight of the material sample, in gram.

\subsubsection{Tannin content (mg TAE/g FW)}

Tannin content was determined by Folin-Denis method (Laitonjam et al., 2013). Each crude extract $(0.5 \mathrm{~mL})$ was taken in a test tube and added distilled water $(0.5 \mathrm{~mL})$. Finally, the samples were treated with $0.5 \mathrm{~mL}$ of freshly prepared FolinDenis reagent and $20 \%$ sodium carbonate $(2 \mathrm{~mL})$ was added, shaken well, warmed on boiling waterbath for 1 minute and cooled to room temperature. The absorbance of the coloured complex was measured at $700 \mathrm{~nm}$. Tannin concentration was quantified based on the calibration curve of tannic acid in ethanol $\left(\mathrm{y}=0.0098 \mathrm{x}+0.0478\right.$ and $\mathrm{R}^{2}$ $=0.9996)$. The tannin content (TC), milligrams of tannic acid equivalents (TAE) per gram fresh weight $(\mathrm{FW})$, was calculated by the following formula:
$\mathrm{TC}(\mathrm{mgTAE} / \mathrm{g})=[(\mathrm{A}-0.0478) \mathrm{x}$ DF $\mathrm{x}$ $\mathrm{V}] /(0.0098 \times \mathrm{W})$

Where A is the absorbance of the test samples; $\mathrm{DF}$ is the dilution factor; $\mathrm{V}$ is volume of the obtained extracts, in litre; $\mathrm{W}$ is the weight of the material sample, in gram.

\subsection{Total soluble solids $(\%)$}

Determination total soluble dry matter content was conducted by following protocol of Giang et al. (2013). Take $30 \mathrm{~mL}$ extract solution to a dried cup that determined weight. The heating in boiled water until the evaporation of water was finished. Then, put it in oven at $100-105^{\circ} \mathrm{C}$, drying until the weight of cup was constant. The content of total soluble solids (TSS) in extract solution was determined by the following formula:

$$
\operatorname{TSS}(\%)=\left[\left(\mathrm{G}_{2}-\mathrm{G}_{1}\right) \times 100\right] / \mathrm{G}
$$

Where $G$ is the weight of test solution, $G_{1}$ is weight of cup, $G_{2}$ is weight of cup and test solution.

\section{Results and Discussion}

The results from Table 1 showed that when the extraction temperature and time changed, the content of bioactive compounds and total soluble solids in the extracts varied accordingly: the anthocyanin content was in the range of $30.15 \div 39.06 \mathrm{mgCE} / 100 \mathrm{~g}$; flavonoid $2.19 \div 3.01$ mgQE/g; polyphenol $3.98 \div 5.18 \mathrm{mgGAE} / \mathrm{g}$; tannin $3.06 \div 4.01 \mathrm{mgTAE} / \mathrm{g} \mathrm{FW}$ (fresh weight); and total soluble solids was from $0.53 \div 0.73 \%$.

Response surface and contour plots in Figure 1 showed the extraction temperature and time had effect on the content of bioactive compounds and soluble solids according to the second-order model with significant levels $(P<0.05)$. When extraction temperature and time increased, the content of bioactive compounds in the extracted solution had increasing trend, and achieved optimal value, then had a decrease. Specifically, the anthocyanin content increased and reached an optimal value of $38.72 \mathrm{mgCE} / 100 \mathrm{~g}$ at $83.7^{\circ} \mathrm{C}$ and $30.3 \mathrm{~min}$ (Figure 1a and 1a'); flavonoid achieved an optimum value of $3.01 \mathrm{mgQE} / \mathrm{g}$ at $84.4^{\circ} \mathrm{C}$ and 33.3 min (Figure 1b and 1b'); polyphenol reached an optimal value of $5.17 \mathrm{mgGAE} / \mathrm{g}$ at $85.6^{\circ} \mathrm{C}$ and 30.6 min (Figure 1c and 1c'); tannin reached an optimum value of $4.10 \mathrm{mgTAE} / \mathrm{g}$ at $87.7^{\circ} \mathrm{C}$ and 34.3 minutes (Figure 1d and 1d'). 


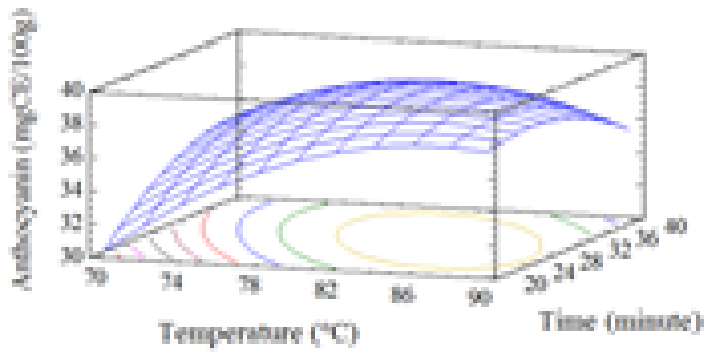

(a)

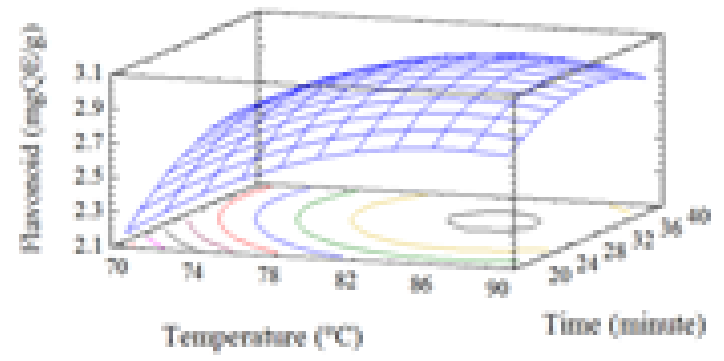

(b)

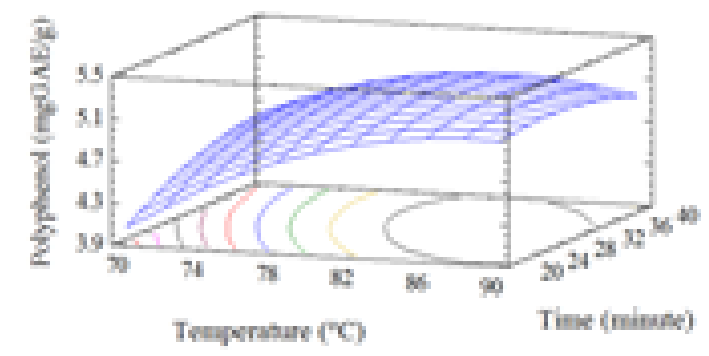

(c)

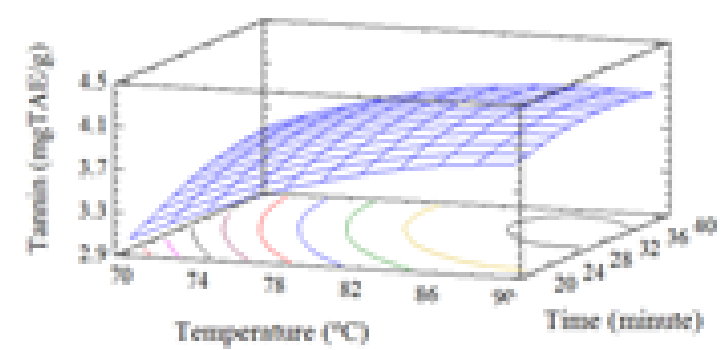

(d)

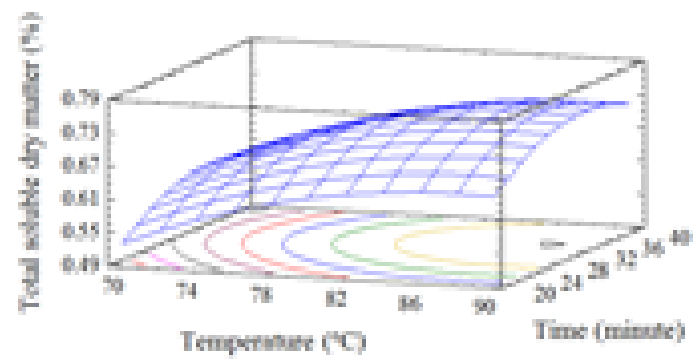

(e)

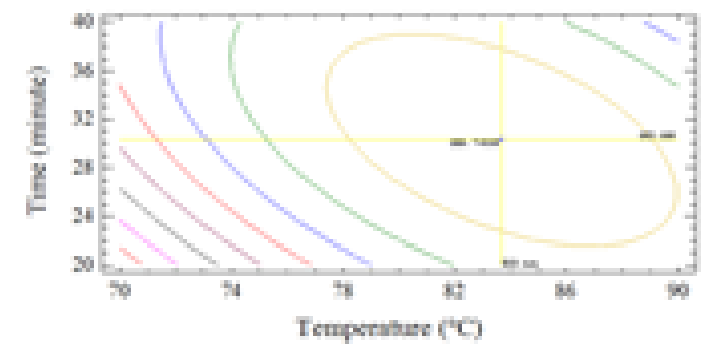

(a')

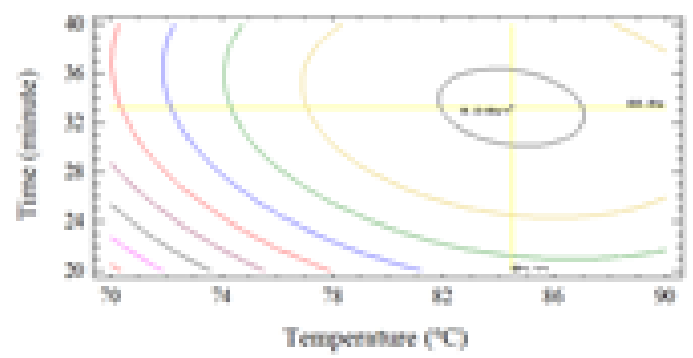

(b)

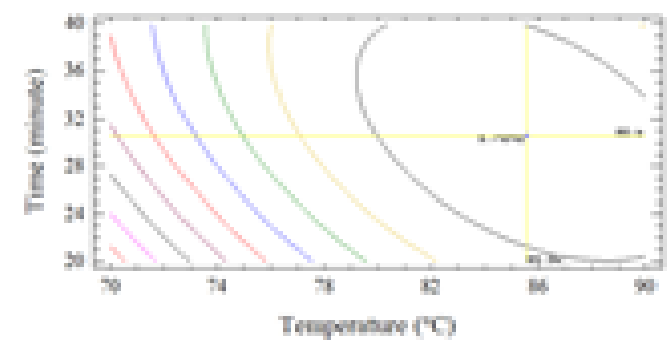

(c)

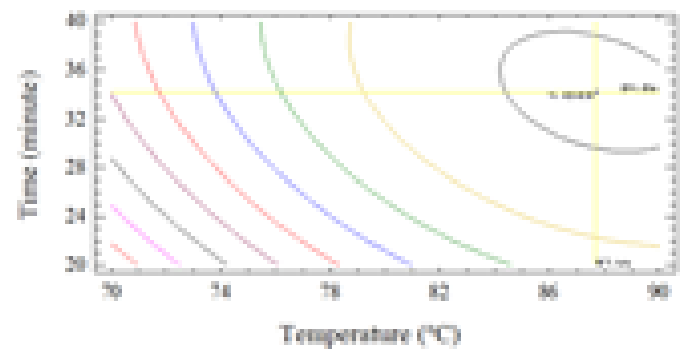

(d')

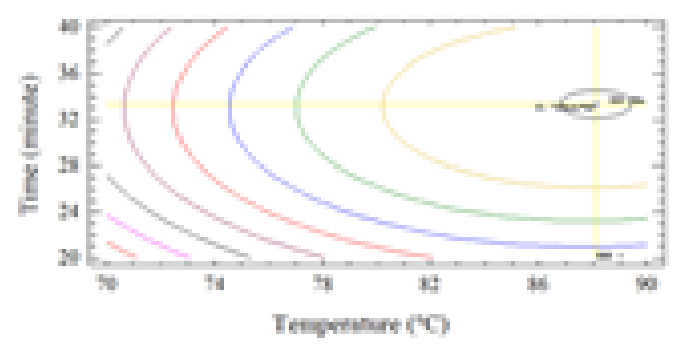

(e")

Figure 1. Response surface and contour plots for the content of anthocyanin (a, a'); flavonoid (b, b'); polyphenol (c, c'); tannin (d, d') and total soluble solids (e, e') in different temperature and time. 

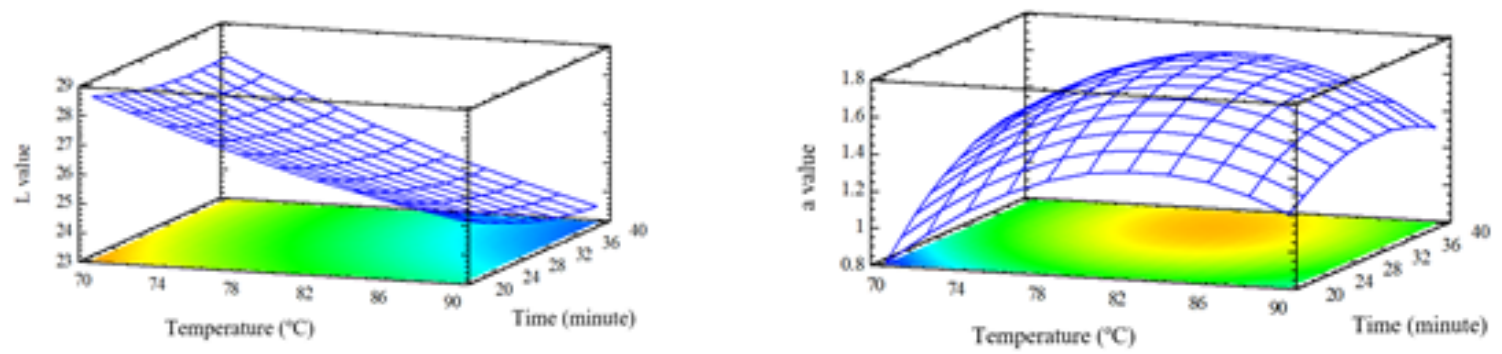

Figure 2. Response surface and contour plots for the color parameters of extract such as L value (a) and a value (b) in different temperature and time.

The results showed that the extraction of bioactive compounds with water solvent was carried out at high temperature $\left(83 \div 87^{\circ} \mathrm{C}\right)$ and short extraction time in the range of $30 \div 34$ minutes. Since most bioactive compounds were sensitive to high temperatures, long extraction time could lead to the decomposition of bioactive compounds ( $\mathrm{Vu} \& \mathrm{Ha}, 2009)$. According to Rajha et al. (2014) extraction of phenolic compounds (polyphenols, flavonoids, tannins and anthocyanins) from grape skins found the optimum extraction parameters of $81^{\circ} \mathrm{C}$ and $140 \mathrm{~min}$ for non-grinding grape grains and $88^{\circ} \mathrm{C}$ for $5 \mathrm{~min}$ grape skins were crushed. Sheng et al. (2013) explained that bioactive compounds were better released from plant cells by reducing the viscosity of the solvent and increasing the molecular motion with increased temperature during extraction. The results of $\mathrm{Vu} \& \mathrm{Ha}$ (2009) showed that the polyphenol content increased when the extraction temperature was increased from $70 \div 90^{\circ} \mathrm{C}$ during the polyphenol extraction process from green tea. The increase of extraction temperature would increase the phenolics extraction efficiency reported by many authors (Spigno \& Faveri, 2007; Spigno et al., 2007; Rajha et al., 2012). Whenever temperature was increased, it reduced surface tension and viscosity, improving the solubility of the solute (Ramos et al., 2002). However, if higher temperature could occur phenolic compounds decompose. The phenolic compounds could avoid composition as the short duration of the extraction process, but high temperatures and long time would have a negative effect on the polyphenol content, oxidation or decomposition could occur (Yilmaz \& Toledo, 2006). Under the effect of oxidation-reduction enzymes, plant tannin was readily oxidized and condensed into colorful or colorless products that directly affected the color of the product (Le, 2003). The appropriate tem- perature for extraction of tannin from bark is between $90 \div 100^{\circ} \mathrm{C}$ (Connolly, 1993). Some authors had shown that the effect of temperature on flavonoid extraction, when the extraction temperature was higher than the optimum temperature, reduced the flavonoid content (Sheng et al., 2013).

Response surface and contour plots in Figures 1e and 1e' showed that the extraction temperature and time also influenced the second order model to the soluble solids content of the extract. Dissolved solids increase with increasing temperature and extraction time and achieved high values in the range of $82 \div 90^{\circ} \mathrm{C}$, dissolved solids reached the optimum value of $0.74 \%$ at $88.1^{\circ} \mathrm{C}$ and $33.4 \mathrm{~min}$. The heat treatment increased the solubility and diffusion of the compounds. The heating decreased the viscosity of the extracting solvent, but it increased the mass transfer and helps the solvent penetrates easily into the cell (Al-Farsi \& Lee, 2008). On the other hand, according to Mohammad et al. (2011), high temperatures could reduce cellular barriers by weakening the walls and cell membranes, making the solvent more easily exposed to the compounds, increasing the ability to extract solutes into the extract solution.

The results in Figure 2a showed that the lightdark (L) value tended to decrease as the temperature and the extraction time was increased. The samples with the darkest color $(\mathrm{L}=23.35)$ at the extraction temperature and time were $94^{\circ} \mathrm{C}$ and $30 \mathrm{~min}$, respectively. The sample had the lightest color $(\mathrm{L}=29.24)$ at $66^{\circ} \mathrm{C}$ and $33 \mathrm{~min}$. Meanwhile, the results in Figure $2 \mathrm{~b}$ showed that the greenred value (a) trended to increase when the extraction time was extended at low temperatures from $66 \div 80^{\circ} \mathrm{C}$ but when raised to $90 \div 94^{\circ} \mathrm{C}$ and extending the extraction time, a value trended to decrease. The highest red color $(\mathrm{a}=1.97)$ was 
extracted at $80^{\circ} \mathrm{C}$ for $44 \mathrm{~min}$ and the lowest red color $(\mathrm{a}=0.89)$ at the temperature and extraction time of $66^{\circ} \mathrm{C}$ and $33 \mathrm{~min}$. This could be explained by increased temperature or prolonged extraction time, which increased the ability to extract color compounds (phenolics compounds) in medicinal plants so that the $\mathrm{L}$ value would decrease (darker color) because $\mathrm{L}$ had value of $100 \div 0$, the value of a would increase (the color would be redder) because a value had green value $(-)$ and $(+)$ is red. However, when the optimum condition was obtained, the phenolics would decompose (especially anthocyanin), reducing the red color of the extract.

In addition, the results of ANOVA statistical analysis of the data in Table 2 showed that the correlation model constructed with linear, interactive and quadratic coefficients of the temperature and time had effect on the anthocyanin, flavonoid, polyphenol, tannin and soluble solids content of the obtained extract with confident level of $95 \%$. In which, the linearity coefficient of the temperature factor had significant effect on the anthocyanin compounds, flavonoid $(P<$ $0.001)$, the time factor had a significant effect $(P$ $<0.01$ ); the coefficient of squared and interaction of temperature and time factors had effect in confident level $(P<0.05)$; except for the interaction coefficient of extraction temperature and time, there was no effect on soluble solids content $(P>0.05)$.

The good correlation model required a match between the actual and theoretical data, so the constructed model with Lack of fit test was not statistically significant (Zabeti et al, 2009). In addition, the correlation model should have a correlation coefficient of $\mathrm{R}^{2}$ greater than 0.8 (Guan $\&$ Yao, 2008). The results in Table 2 showed that the correlation coefficient of the predicted models was $\mathrm{R}^{2}>0.951$ and the $P$ for lack of fit was $0.1379>0.05$. The model's suitability was very high and there was good compatibility between experimental and predictive data (Figure 3).

\subsection{Multiple response optimization}

Extraction was widely known as an extraction process of bioactive substances from plant materials. Several factors could contribute to the effects of bioactive compounds extracted, including the method of extraction, temperature and extraction time, rate of materials and solvent (Pinelo et al., 2005a \& 2005b; Chew et al., 2011).

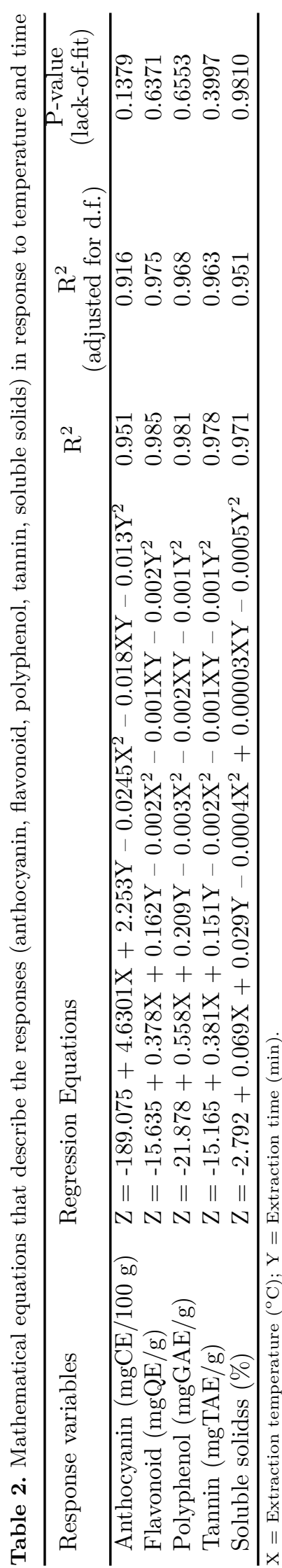



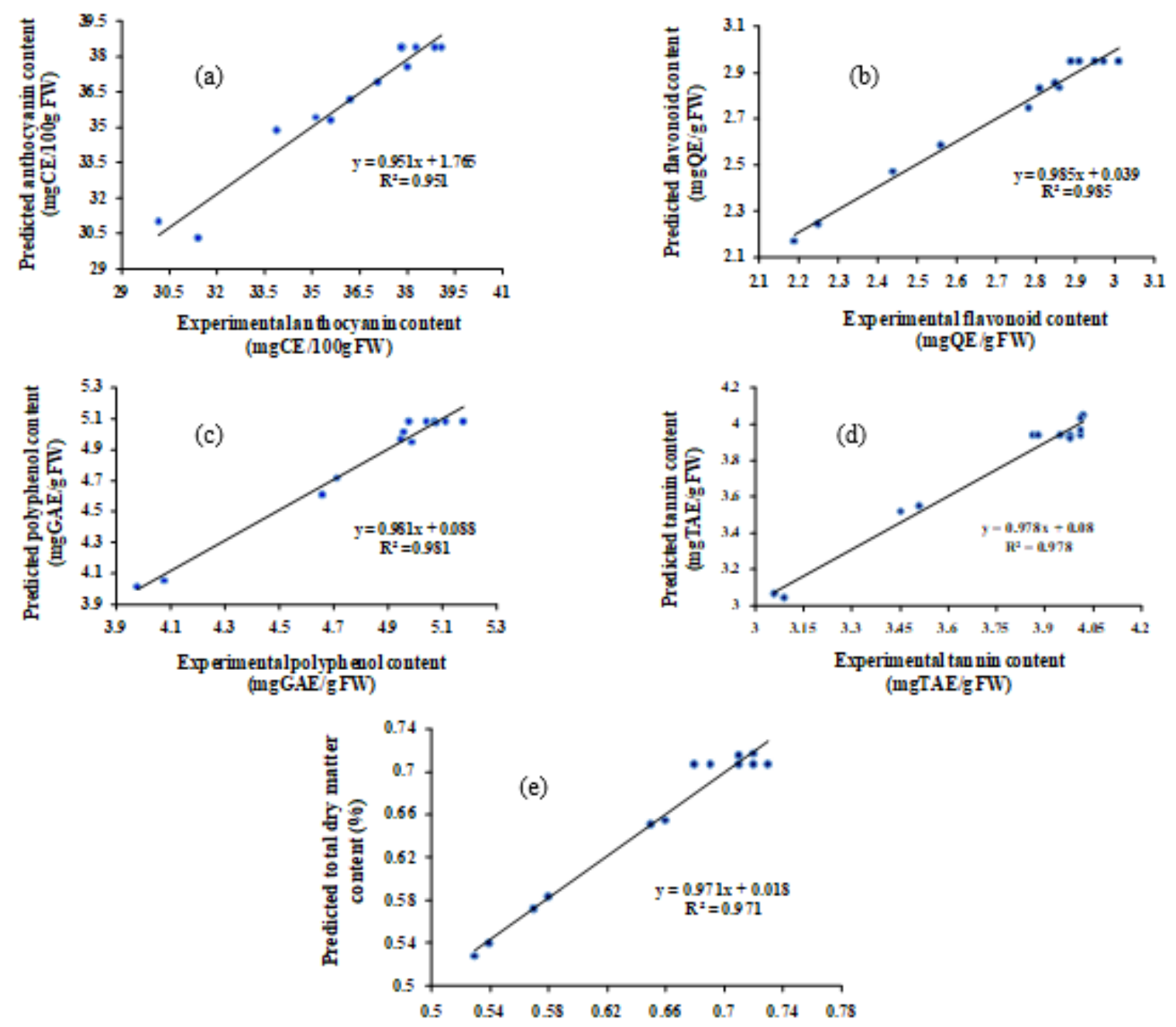

Experimental totaldry ma tter content $(\%)$

Figure 3. Correlation between the experimentally and the estimated values for anthocyanin (a), flavonoid (b), a polyphenol (c), tannin (d) and total soluble solids (e) using the models described in equation 1, 2, 3, 4,5 ; respectively (as shown in Table 2).

The responses (anthocyanin, flavonoid, polyphenol, tannin and soluble solids content) were optimized separately, therefore allowing the targeting of a certain class of compounds only by varying the extraction parameters. Yet, the desirability function in the RSM was utilized to reveal the combination of the parameters (temperature and time) capable of simultaneously maximizing all the responses. The overplay plot (Figure 4) showed the outlines superposition of all the studied responses and the simultaneous optimum for all responses was showed by the black spot.

The optimum extraction parameters were ob- tained from the model with a temperature of $84.4^{\circ} \mathrm{C}$ and a time of $31.7 \mathrm{~min}$. At this optimal extraction parameter, the content of the anthocyanin, flavonoid, polyphenol, tannin and dissolved solids was 38,66 $\mathrm{mgCE} / 100 \mathrm{~g} ; 3.01$ $\mathrm{mgQE} / \mathrm{g} ; 5.17 \mathrm{mgGAE} / \mathrm{g} ; 4.07 \mathrm{mgTAE} / \mathrm{g}$ fresh weight and $0.73 \%$, respectively.

\subsection{Test the predicted values from the model}

To test the optimal values obtained from the predicted models, the study performed according to the best parameters found: extraction at $85^{\circ} \mathrm{C}$ for $32 \mathrm{~min}$; then filtered and retrieved the extract and conduct analyzed to determine the 


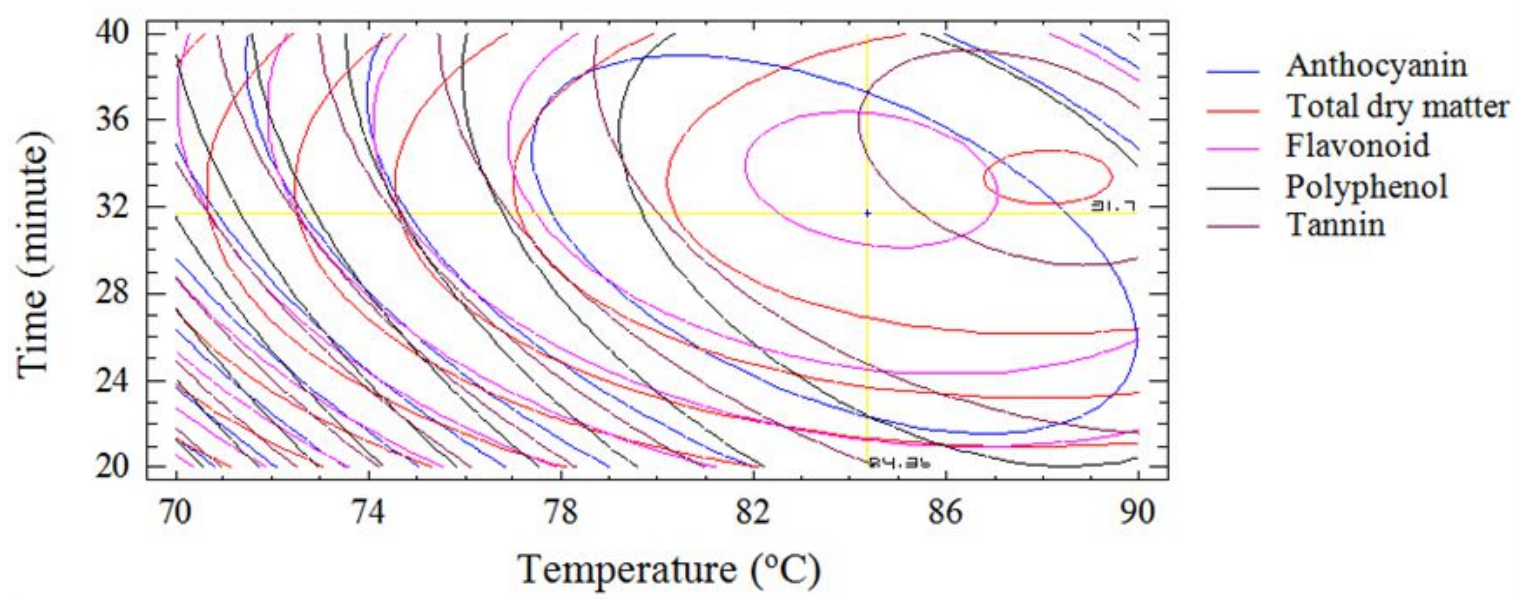

Figure 4. Superposition contour plots, showing the best experimental parameters that maximize bioactive compounds content and total dry matter of extract solution (the black spot shows the optimum for all the responses).

Table 3. Comparison of test values with calculated values of optimal models

\begin{tabular}{clccc}
\hline No. & Analytical targets & Test value* & Calculated value & $\begin{array}{c}\text { Differential } \\
\text { percentage (\%) }\end{array}$ \\
\hline 1 & Anthocyanin (mgCE/100 g FW) & $37.19 \pm 0,97$ & 38.66 & 3.80 \\
2 & Flavonoid (mgQE/g FW) & $3.14 \pm 0,07$ & 3.01 & 4.14 \\
3 & Polyphenol (mgGAE/g FW) & $5.25 \pm 0,19$ & 5.17 & 1.52 \\
4 & Tannin (mgTA/g FW) & $3.94 \pm 0,15$ & 4.07 & 3.19 \\
5 & Soluble solids (\%) & $0.71 \pm 0,01$ & 0.73 & 2.74 \\
\hline
\end{tabular}

(*) Mean value $(\mathrm{n}=3)$ and \pm SD (Standard Deviation).

content of bioactive compounds and dissolved solids. The content of anthocyanin, tannin and dissolved solids were lower than predictive values by $3.80 \% ; 3.19 \%$ and $2.74 \%$. Meanwhile, the levels of flavonoid and polyphenol were higher than predictive values by $4.14 \%$ and $1.52 \%$ respectively (Table 3 ). The difference was within the allowable limit $(<5 \%)$. The result of this difference was that the optimum extraction conditions of the compounds found in the model were between $83.7 \div 88.1^{\circ} \mathrm{C}$ and $30.3 \div 34.3$ minutes.

\section{Conclusions}

Response Surface Methodology (RSM) is a highly reliable method in predicting optimizing models. Using RSM to find the most suitable temperature and time to extract bioactive compounds and soluble solids at the same time could minimize the degradation of these bioactive substances. Therefore it could improve the quality of compounds after the extraction. The extraction temperature and time were $85^{\circ} \mathrm{C}$ and $32 \mathrm{~min}$.
At this condition, the content of anthocyanin, flavonoid, polyphenol, tannin and soluble solids were $37.19 \mathrm{mgCE} / 100 \mathrm{~g} ; 3.14 \mathrm{mgQE} / \mathrm{g} ; 5.25 \mathrm{mg}$ $\mathrm{GAE} / \mathrm{g} ; 3.94 \mathrm{mgTAE} / \mathrm{g}$ fresh weight, $0.71 \%$, respectively. This method could become an alternative technique to apply in solid-liquid extraction the bioactive compounds in Pouzolzia zeylanica at the industrial scale.

\section{References}

Ahmed, J. K., Salih, H. A. M., \& Hadi, A. G. (2013). Anthocyanin in red beet juice act as scavenger for heavy metals ions such as lead and cadmium. International Journal of Science and Technology 2(3), 269-273.

Al-Farsi, M. A., \& Lee, C. Y. (2008). Optimization of phenolics and dietary fibre extraction from date seeds. Food Chemistry 108, 977-985.

Chew, K. K., Ng, S. Y., Thoo, Y. Y., Khoo, M. Z., Wan, W. M. A., \& Ho, C. W. (2011). Effect of ethanol concentration, extraction time and extraction temperature on the recovery of phenolic compounds and antioxidant capacity of Orthosiphon stamineus extracts. International Food Research Journal 18, 1427-1435. 
Connolly, D.L. (1993). Tannin extraction. US Patent 5, 238-680.

Eswari, M. L., Bharathi, R. V., \& Jayshree, N. (2013). Preliminary phytochemical screening and heavy metal analysis of leaf extracts of Ziziphus oenoplia (L) Mill. Gard. International Journal of Pharmaceutical Sciences and Drug Research 5(1), 38-40.

Giang, H. T., Nguyen, H. T., Ngo, M. X., Nguyen, T. T. B., Pham, N. D., Nguyen, O. T., Phan, H. T., \& Duez, P. (2013). Effects of raw material types on the chemical composition of Trung Du tea variety (Camellia sinensis var. sinensis). Journal Science \& Development 11(3), 373-379.

Guan, X., \& Yao, H. (2008). Optimization of viscozyme L assisted extraction of oat bran protein using response surface methodology. Food Chemistry 106, 345-351.

Handa, S. S., Khanuja, S. P. S., Longo, G., \& Rakesh, D. D. (2008). Extraction technologies for medicinal and aromatic plants ( $1^{\text {st }}$ ed.). Trieste, Italy: United Nations Industrial Development Organization and the International Centre for Science and High Technology.

Hossain, M. A., Raqmi, K. A. S., Mijizy, Z. H., Weli, A. M., \& Riyami, Q. (2013). Study of total phenol, flavonoids contents and phytochemical sreening of various leaves crude extracts of locally grown Thymus vularis. Asian Pacific Journal of Tropical Biomedicine 3(9), 705-710.

Laitonjam, W. S., Yumnam, R., Asem, S. D., \& Wangkheirakpam, S. D. (2013). Evaluative and comparative study of biochemical, trace elements and antioxidant activity of Phlogacanthus pubinervius T. Anderson and Phlocanthus jenkincii C.B. Clarke leaves. Indian Journal of Natural Products and Resources 4(1), 67-72.

Le, T. N. (2003). Food Chemistry. Ha Noi, Vietnam: Publishing House of Science and Technology.

Mohammad, K., Hefazat, H. S. \& Sheeba, F. (2011). Free radical scavenging and total phenolic content of Saccharum spontaneous L. root extracts. International Journal of Research in Pharmacy and Chemistry 1(4), 1160-1166.

Pinelo, M., Fabbro, P. D., Manzocco, L., Nunez, M. J., \& Nicoli, M. C. (2005a). Optimization of continuous phenol extraction from vitisvinifera byproducts. Food Chemistry 92(1), 109-117.

Pinelo, M., Rubilar, M., Jerez, M., Sineiro, J., \& Nunez, M. J. (2005b). Effect of solvent, temperature, and solvent-to-solid ratio on the total phenolic content and antiradical activity of extracts from different components of grapepomace. Journal of Agricultural and Food Chemistry 53(6), 2111-2117.

Rajha, H. N., Darra, N. E., Louka, N., Maroun, R. G., Ziegler, W., \& Bochzelt, H. (2012). Valorization of industrial waste using energy saving procedures. Phenolic compounds purification from grape by-products by accelerated solvent extraction (ASE). International Conference on Renewable Energies for Developing Countries, 1-5.
Rajha, H. N., Louka, N., Darra, N. E., Hobaika, Z., Boussetta, N., Vorobiev, E., \& Maroun, R. G. (2014). Multiple response optimization of high temperature, low time aqueous extraction process of phenolic compounds from grape byproducts. Food and Nutrition Sciences 5, 351-360.

Ramos, L., Kristenson, E. M., \& Brinkman, U. A. (2002). Current use of pressurised liquid extraction and subcritical water extraction in environmental analysis. Journal of Chromatography A 975(1), 3-29.

Saha, D., \& Paul, S. (2012). Antifungal activity of ethanol extract of Pouzolzia Zeylanica (L.) Benn. International Journal of Pharmacy Teaching and Pratices 3(2), 272274 .

Saha, D., Paul, S., \& Chowdhury, S. (2012). Antibacterial activity of ethanol extract of Pouzolzia Zeylanica (L.) Benn. International Journal of Pharmaceutical Innovations (IJPI) 2(1), 1-5.

Sheng, Z. L., Wan, P. F., Dong, C. L., \& Li, Y. H. (2013). Optimization of total flavonoids content extracted from Flos populi using response surface Methodology. Industrial Crops and Products 43, 778-786.

Spigno, G., \& De-Faveri, D. M. (2007). Antioxidants from grape stalks and marc: influence of extraction procedure on yield, purity and antioxidant power of the extracts. Journal of Food Engineering 78(3), 793-801.

Spigno, G., Tramelli, L., \& De-Faveri, D. M. (2007). Effects of extraction time, temperature and solvent on concentration and antioxidant activity of grape marc phenolics. Journal of Food Engineering 81(1), 200-208.

Tran, T. T. M., Nguyen, H. T. T., Duong, N. T. M., Tran, L. C., \& La, K. V. (2010). Experimental study on some pharmacological effects of Pouzolzia zeylanica and Tinospora crispa. Medicine Journal of Ho Chi Minh City, Special Subject Traditional Medicine 14(2), 116-120.

Vo, C. V. (2012). Dictionary medicinal plants in Vietnam. Ha Noi, Vietnam: Medicine Publishing House.

Vu, S. H., \& Ha, T. D. (2009). Study on polyphenol extraction from dust green tea. Part 1. The influence factors on polyphenol extraction. Journal of Science and Technology 47(1), 81-86.

Vyas, J., Itankar, P., Tauqeer, M., Kelkar, A., \& Agrawal, M. (2013). Development of HPTLC method for estimation of piperine, guggulsterone $\mathrm{E}$ and $\mathrm{Z}$ in polyherbal formulation. Pharmacognosy Journal 5(6), 259-264.

Yilmaz, Y., \& Toledo, R. T. (2006). Oxygen radical absorbance capacities of grape/wine industry by products and effect of solvent type on extraction of grape seed polyphenols. Journal of Food Composition and Analysis 19(1), 41-48.

Zabeti, M., Daud, W. M. A., \& Aroua, M. K. (2009). Optimization of the activity of $\mathrm{CaO} / \mathrm{Al} 2 \mathrm{O} 3$ catalyst for biodiesel production using response surface methodology. Applied Catalysic A: General 366(1), 154-159. 